\title{
Werdnig-Hoffmann Disease
}

National Cancer Institute

\section{Source}

National Cancer Institute. Werdnig-Hoffmann Disease. NCI Thesaurus. Code $C 98670$.

The most severe form of spinal muscular atrophy. It is manifested in the first year of life with muscle weakness, poor muscle tone, and lack of motor development. The motor neuron death affects the major organ systems, particularly the respiratory system. Most patients die before the age of two secondary to pneumonia. 